\title{
Molecular and Biochemical Characterization of a Bimodular Xylanase From Marinifilaceae Bacterium Strain SPP2
}

\author{
Zhenggang Hant, Fang Shang-guant and Jiangke Yang* \\ College of Biology and Pharmaceutical Engineering, Wuhan Polytechnic University, Wuhan, China
}

OPEN ACCESS

Edited by:

Kian Mau Goh,

University of Technology Malaysia,

Malaysia

Reviewed by:

Zunxi Huang,

Yunnan Normal University, China

Renaud Berlemont,

California State University,

Long Beach, United States

*Correspondence:

Jiangke Yang

jiangke.yang@gmail.com

tThese authors have contributed equally to this work

Specialty section:

This article was submitted to Microbiotechnology, Ecotoxicology and Bioremediation,

a section of the journal

Frontiers in Microbiology

Received: 02 March 2019

Accepted: 17 June 2019

Published: 02 July 2019

Citation:

Han Z, Shang-guan F and Yang J (2019) Molecular and Biochemical

Characterization of a Bimodular Xylanase From Marinifilaceae

Bacterium Strain SPP2.

Front. Microbiol. 10:1507.

doi: 10.3389/fmicb.2019.01507
In this study, the first xylantic enzyme from the family Marinifilaceae, XynSPP2, was identified from Marinifilaceae bacterium strain SPP2. Amino acid sequence analysis revealed that XynSPP2 is a rare Fn3-fused xylanase, consisting of a signal peptide, a fibronectin type-III domain (Fn3), and a C-terminal catalytic domain belonging to glycoside hydrolase family 10 (GH10). The catalytic domain shared $17-46 \%$ identities to those of biochemically characterized $\mathrm{GH} 10$ xylanases. Structural analysis revealed that the conserved asparagine and glutamine at the glycone $-2 /-3$ subsite of $\mathrm{GH} 10$ xylanases are substituted by a tryptophan and a serine, respectively, in XynSPP2. Fulllength XynSPP2 and its Fn3-deleted variant (XynSPP2 $\triangle F n 3)$ were overexpressed in Escherichia coli and purified by Ni-affinity chromatography. The optimum temperature and $\mathrm{pH}$ for both recombinant enzymes were $50^{\circ} \mathrm{C}$ and 6 , respectively. The enzymes were stable under alkaline condition and at temperature lower than $50^{\circ} \mathrm{C}$. With beechwood xylan as the substrate, XynSPP2 showed 2.8 times the catalytic efficiency of XynSPP2 $\triangle F n 3$, indicating that the Fn3 module promotes xylanase activity. XynSPP2 was active toward xylooligosaccharides (XOSs) longer than xylotriose. Such a substrate preference can be explained by the unique $-2 /-3$ subsite composition in the enzyme which provides new insight into subsite interaction within the GH10 family. XynSPP2 hydrolyzed beechwood xylan into small XOSs (xylotriose and xylotetraose as major products). No monosaccharide was detected by thin-layer chromatography which may be ascribed to putative transxylosylation activity of XynSPP2. Preferring long XOS substrate and lack of monosaccharide production suggest its potential in probiotic XOS manufacture.

Keywords: Fn3 domain, glycoside hydrolase, Marinifilaceae bacterium, xylanase, xylooligosaccharide

\section{INTRODUCTION}

Plant material mainly consists of cellulose, hemicellulose, and lignin (Tuck et al., 2012). Xylan, a $\beta$ 1,4-linked xylopyranose polymer, is the most common constituent of hemicellulosic polysaccharide in the biosphere (Linares-Pasten et al., 2018). Intensive research focused on developing different innovative technologies to exploit xylan (Van Dyk and Pletschke, 2012). Enzymatic decomposition is attractive because it is environmentally friendly. Xylan biodegradation is carried out by many 
hydrolytic enzymes. Among them, the enzymes that randomly break down the internal glycosidic bond in the linear xylan main chain are termed endo- $\beta$-1,4-xylanases (EC. 3.2.1.8, normally referred to as xylanases) (Nguyen et al., 2018).

Xylanases from diverse groups of microorganisms have attracted increasing attention in the last few decades because of their enormous biotechnological potential in a wide variety of industrial processes (Linares-Pasten et al., 2018). Xylanases have been applied in lignocellulose materials saccharification (preparing fermentable sugars) (Basit et al., 2018a), animal feeds (as additives) (Ndou et al., 2015), chlorine-free bleaching of wood pulp (Thomas et al., 2015), and brewer's spent grain saccharification (Amor et al., 2015). In addition, the production of xylooligosaccharides (XOSs) as putative prebiotics using xylanases has obtained increasing interest (Morgan et al., 2017; Linares-Pasten et al., 2018; Nordberg Karlsson et al., 2018). XOSs with a degree of polymerization between 2 and 10 units demonstrate great prebiotic effects and are potential ingredients in food and pharmaceutical preparations (Aachary and Prapulla, 2011; Nieto-Domínguez et al., 2017).

In the Carbohydrate Active Enzymes database $\left(\mathrm{CAZY}^{1}\right)$, the most characterized xylanases are mainly grouped into glycoside hydrolase families 10 and 11 (GH10 and GH11) according to the amino acid sequence homologies of their catalytic domains (Lombard et al., 2014; Nguyen et al., 2018). Compared with GH11 xylanases, GH10 xylanases have a broader substrate specificity. In addition, they are active on the decorated heteroxylans to some extent, producing smaller enzymatic products than GH11 xylanases (Pollet et al., 2010). GH10 xylanases exhibit an $(\beta / \alpha)_{8}$ barrel structure that folds into a bowl shape. A set of xylose-binding subsites arranged on the outside surface of xylanases determines the position-specific binding and cleavage of a substrate. The glycosidic bond linking the xylose residues at the -1 and +1 subsites is cleaved. In general, the subsites at the glycone region are well conserved and strong in xylose residue binding, whereas the subsites at the aglycone region are less conserved and weak in xylose residue binding.

Different from GH11 xylanase, GH10 xylanases generally show higher activity on small XOS molecules (including xylotriose) and produce XOS with lower degree of polymerization (X2-X5) and xylose (Linares-Pasten et al., 2018). Being active toward small XOSs and producing of monosaccharide to some extent are disadvantages for specific application of xylanase, such as probiotic XOS manufacture. Structural study has shown that the shortest hydrolysable substrate for catalysis is determined by subsite interactions at the glycone region of substrate-binding cleft (Schmidt et al., 1999). A small number of amino acid variations in the substrate-binding cleft of a subset of GH10 xylanases, mostly the $-2 /-3$ region (distal amino acids constituting the -2 subsite), confers subtle differences in substrate specificity and cleavage pattern to the enzymes compared with the other GH10 xylanases (Andrews et al., 2000; Pell et al., 2004). For example, a Glu/Gly substitution at the $-2 /-3$ subsite of CjXyn10C from Cellvibrio japonicus alerts the affinity for XOSs but does not impair the affinity

${ }^{1}$ http://www.cazy.org/ for long substrates (xylan); in addition, a tyrosine insertion at the $-2 /-3$ subsite of CjXyn10C changes the cleavage pattern of xylotetraose from " -2 to +2 " to " -3 to +1 " (Pell et al., 2004). Accordingly, to screen the xylanases harboring unique variations within the substrate-binding cleft is an effective way to characterize xylanases with changed substrate preference and product pattern.

Current advances in microbial genome or metagenome sequencing provide opportunities to identify a large number of xylanases with novel sequences (Basit et al., 2018b). Enzymes from marine microorganisms have attracted considerable attention because they are possibly unique in primary sequence and biochemical property (Kennedy et al., 2008; Trincone, 2011). Therefore, we provided special attention to uncharacterized xylanases in the genome of marine microorganisms. A putative GH10 xylanase, XynSPP2 from Marinifilaceae bacterium strain SPP2, was recently isolated from the Antarctic marine sediment (Watanabe et al., 2018). The xylanase particularly attracted our attention due to its unique architecture at glycone subsites as revealed by multiple amino acid sequence alignment and 3-D structure modeling. The present paper reports the bioinformatic and biochemical characterization of XynSPP2. It is also the first xylantic enzyme from the family Marinifilaceae. Amino acid sequence analysis suggested that XynSPP2 consists of a fibronectin type 3 (Fn3) domain and a GH10 catalytic domain. Recombinant full-length XynSPP2 and GH10 domain (XynSPP2 $\Delta$ Fn3) were produced by Escherichia coli system. Xylanase assay showed that the Fn3 domain contributes to the catalytic efficiency of XynSPP2. Thin-layer chromatography (TLC) indicated recombinant XynSPP2 displayed very weak activity toward xylotriose and preferred cleaving xylotetraose in a " $-3,+1$ " mode. Such a hydrolytic property is different from the general characteristic of GH10 xylanases. Structural analysis suggested unique $-2 /-3$ subsite in XynSPP2 may account for its unique hydrolytic property which provides new insight into subsite interaction of GH10 xylanase. In addition, no monosaccharide was detected by TLC assay. All of these properties suggest that XynSPP2 is suitable for XOS production.

\section{MATERIALS AND METHODS}

\section{Materials}

Nucleotide sequence encoding of XynSPP2 was obtained from the genome of $M$. bacterium strain SPP2 (GenBank accession number: NZ_AP018042.1). DNA fragments of XynSPP2 were synthesized by GENEWIZ Suzhou (Suzhou, China) after codon optimization (designed for recombinant protein production in $E$. coli using Codon OptimWiz software developed by GENEWIZ). The nucleotide sequence of codonoptimized XynSPP2 has been deposited in GenBank under the accession number of MK722389. Beechwood xylan and XOSs (xylobiose, xylotriose, xylotetraose, xylopentaose, and xylohexaose) were purchased from Megazyme Corp (Wicklow, Ireland). Molecular mass standards were purchased from Bio-Rad Laboratories (Shanghai, China). 


\section{Amino Acid Sequence Analysis and Structure Homology Modeling}

Signal peptide and functional domain annotation was performed using SignalP-5.0 ${ }^{2}$ (Almagro Armenteros et al., 2019) and Conserved Domain Search ${ }^{3}$ (Marchler-Bauer et al., 2017), respectively. GenBank database search for XynSPP2 sequence (GenBank accession number: WP_096428726.1) analysis was carried out using BLASTp ${ }^{4}$. Amino acid sequence (full-length enzymes or their GH10 domains) comparison between XynSPP2 and characterized GH10 xylanases to date (320 sequences were used) ${ }^{5}$ was conducted using Clustal Omega ${ }^{6}$ (Sievers et al., 2011). A phylogenetic tree of the GH10 domains of the characterized xylanases was constructed using MEGA 7 (Kumar et al., 2016). Conserved amino acid residues in the active-site cleft of the GH10 xylanases was demonstrated using WebLogo (Crooks et al., 2004) on the basis of the result of the GH10 domain alignment. An alignment of GH10 domains of 10 representative xylanases [all of their X-ray structures are available in Protein Data Bank (PDB)] was performed to prepare an alignment figure (Figure 1). A 3-D structural model of XynSPP2 was built by homology modeling using SWISS-MODEL ${ }^{7}$ (Waterhouse et al., 2018). The quality of the resulting model was evaluated by MolProbity (Chen et al., 2010). Structural graphics were prepared using PyMOL (Schrödinger LLC, Cambridge, MA, United States).

\section{Recombinant XynSPP2 Production and Purification}

E. coli DH5a (Thermo Fisher Scientific, Shanghai, China) was used for cloning. Full-length XynSPP2 and catalytic domain (XynSPP2 $\triangle \mathrm{Fn} 3)$ were subcloned into the expression vector pET-28a (Novagen, San Diego, CA, United States). Overnight cultures of E. coli BL21 (DE3) cells (Thermo Fisher Scientific, Shanghai, China) harboring recombinant plasmids (pET-28aXynSPP2 or pET-28a-XynSPP2 $\Delta$ Fn3) were prepared to inoculate $200 \mathrm{ml}$ of ZYM 5052 autoinduction medium supplemented with $100 \mu \mathrm{g} / \mathrm{ml}$ kanamycin, and $34 \mu \mathrm{g} / \mathrm{ml}$ chloramphenicol in a $2 \mathrm{~L}$ shake flask (Studier, 2005). After 4-h incubation at $37^{\circ} \mathrm{C}$ and $250 \mathrm{rpm}$, the cultures were cooled and further incubated for $24 \mathrm{~h}$ at $20^{\circ} \mathrm{C}$ before harvested by centrifugation. The pellet was resuspended in sodium phosphate buffer $(50 \mathrm{mM}$, $\mathrm{pH} 7$ ), and the cells were broken by sonication. The cellfree extract was obtained by centrifugation at $25,000 \times g$ for $30 \mathrm{~min}$ at $4^{\circ} \mathrm{C}$. Protein purification was conducted by $\mathrm{Ni}$ affinity chromatography as described previously (Han et al., 2018). The homogeneity of the recombinant protein was checked by sodium dodecyl sulfate-polyacrylamide gel electrophoresis (SDS-PAGE). The pure fractions were pooled and protein concentration was determined by Bradford using bovine serum albumin as the standard.

\footnotetext{
${ }^{2}$ http://www.cbs.dtu.dk/services/SignalP/

${ }^{3}$ https://www.ncbi.nlm.nih.gov/Structure/cdd/wrpsb.cgi

${ }^{4}$ https://blast.ncbi.nlm.nih.gov/Blast.cgi

${ }^{5} \mathrm{http} / / /$ www.cazy.org/GH10_characterized.html

${ }^{6} \mathrm{https} / / / \mathrm{www} . e b i . a c . u k /$ Tools/msa/clustalo/

${ }^{7} \mathrm{http} / / /$ swissmodel.expasy.org/
}

\section{Xylanase Activity Assays}

Xylanase activities were measured with beechwood xylan as the substrate. Each reaction mixture contained $100 \mu \mathrm{l}$ of beechwood xylan $(10 \mathrm{mg} / \mathrm{ml}), 100 \mu \mathrm{l}$ of diluted purified XynSPP2 or XynSPP2 $\Delta \mathrm{Fn} 3(20 \mu \mathrm{g} / \mathrm{ml})$, and $200 \mu \mathrm{l}$ of citrate-phosphate buffer $(200 \mathrm{mM}, \mathrm{pH}$ 6). The reactions were performed at $50^{\circ} \mathrm{C}$ for $10 \mathrm{~min}$ and stopped by adding $200 \mu \mathrm{l}$ dinitrosalicylic acid. Xylanase activity was routinely quantified by determining the reducing sugar released from reactions with xylose as the standard (Bailey et al., 1992). Each assay was performed in triplicate. One unit of xylanase activity was defined as the amount of enzyme that is able to release $1 \mu \mathrm{mol}$ xylose per minute under the assay condition.

\section{Effects of Temperature and pH on Xylanase Activity}

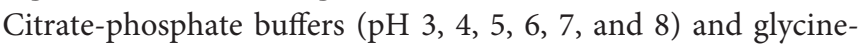
$\mathrm{NaOH}$ buffers $(100 \mathrm{mM}, \mathrm{pH} 9,10$, and 11) were used to determine the $\mathrm{pH}$ profile of the recombinant xylanases. The optimum temperature was determined by measuring the xylanase activities at $\mathrm{pH} 6$ for $10 \mathrm{~min}$ over the range from 10 to $70^{\circ} \mathrm{C}$.

\section{Thermal Stability and pH Stability of Recombinant Xylanases}

Thermal stability was evaluated by measuring the residual activity at the optimum conditions $\left(50^{\circ} \mathrm{C}\right.$ and $\mathrm{pH}$ 6) after incubating xylanase at different temperatures for $1 \mathrm{~h}$. To analyze the stability at different $\mathrm{pH}$ values, the enzymes were incubated at $\mathrm{pH} 3-11$ and $20^{\circ} \mathrm{C}$ for $1 \mathrm{~h}$ before subjecting them to the activity assay under optimal conditions. Purified enzymes were sufficiently diluted with buffers to ensure that the desired $\mathrm{pH}$ values were obtained at incubation and assay steps. In specific, for each assay, $0.5 \mu \mathrm{l}$ of purified enzyme was at least 20 times diluted with buffers of different $\mathrm{pH}$ values for incubation, and the enzymes after incubation (about $20 \mu \mathrm{l}$ ) were subjected to xylanase assay (200 $\mu \mathrm{l}$ buffer of $\mathrm{pH} 6$ was in the reaction mixture).

\section{Effects of Metal lons, Chemical Reagents, and Salt Concentration on Xylanase Activity}

The effects of different chemical reagents on xylanase activity were measured at $50^{\circ} \mathrm{C}$ and $\mathrm{pH} 6$ for 10 min using purified XynSPP2. Each metal ion (prepared using $\mathrm{CaCl}_{2}, \mathrm{CoCl}_{2}$, $\mathrm{FeSO}_{4}, \mathrm{MgSO}_{4}, \mathrm{ZnSO}_{4}, \mathrm{NiSO}_{4}$, and $\mathrm{MnCl}_{2}$ ) was added at a final concentration of $5 \mathrm{mM}$. Then, $5 \%$ (glycerol, $n$-butanol, ethanol, methanol, isopropanol, and acetone) or 10\% [acetone and dimethyl sulfoxide (DMSO)] of organic solvent was added individually to the reaction to study their effects on xylanase activity. The effects of ethylenediaminetetraacetic acid (EDTA) (10 $\mathrm{mM})$, dithiothreitol (DTT) (10 $\mathrm{mM})$, $\beta$-mercaptoethanol ( $\beta$-ME) $\quad(0.5 \%), \quad$ Triton $\quad \mathrm{X}-100 \quad(0.5 \%)$, sodium dodecyl sulfate (SDS) $(10 \mathrm{mM})$, urea $(100 \mathrm{mM})$, ammonium sulfate $(100 \mathrm{mM})$, and guanidine hydrochloride $(\mathrm{GuHCl})(100 \mathrm{mM})$ were also investigated. $\mathrm{NaCl}$ were 




FIGURE 1 | Multiple sequence alignment of GH10 domains of XynSPP2 and representative xylanases. Amino acid sequences were aligned using Clustal Omega. Strictly conserved and similar amino acids are shown in black and gray background, respectively. The numbers of amino acids refer to XynSPP2. The GH10 domain sequences are represented by GenBank accession numbers of their intact proteins, with AAD35164.1 for xylanase from Thermotoga maritima MSB8 (TmxB), AAV98623.1 for xylanase from Bacillus halodurans, ACM59337.1 for xylanase from Caldicellulosiruptor bescii DSM 6725 (CbXyn10B), AEA30147.1 for xylanase from Cellulomonas fimi ATCC 484 (CfXyn10A), ACE84815.1 for xylanase from Cellvibrio japonicus Ueda107 (CjXyn10C), BAA02069.1 for xylanase from Clostridium stercorarium; ABI49951.1 for xylanase from Geobacillus stearothermophilus (XT6), CAA07174.1 for xylanase from Paenibacillus barcinonensis (PbXyn10B), AAC45554.1 for xylanase from Streptomyces halstedii, AAM39089.1 for xylanase from Xanthomonas citri, and AYC81220.1 for xylanase from uncultured bacterium. Red and blue arrows highlight the putative catalytic amino acids (acid/base catalyst and nucleophile) and amino acid residues involved in xylose residue binding, respectively.

added at a final concentration of $0.5-2.5 \mathrm{M}$ to study the salt tolerance of XynSPP2.

\section{Kinetic Parameter Determination}

The reactions to determine the values of maximum velocity $\left(V_{\max }\right)$, Michaelis-Menten constant $\left(K_{m}\right)$, and turnover number $\left(k_{\text {cat }}\right)$ for XynSPP2 were performed at $50^{\circ} \mathrm{C}$ in citratephosphate buffer $(\mathrm{pH}$ 6) for 5 min. Beechwood xylan was used as the substrate at concentrations ranging from 0.5 to $6 \mathrm{mg} / \mathrm{ml}$. $V_{\max }$ and $K_{m}$ were determined using the Lineweaver-Burk method. The $k_{\text {cat }}$ value was calculated from the $V_{\text {max }}$ value according to the amount of enzyme used in the reaction.

\section{Hydrolytic Products Determination by Thin-Layer Chromatography}

The hydrolytic products of XynSPP2 against XOSs were detected by TLC. The reaction mixtures included $0.5 \mu \mathrm{g}$ of purified enzyme, and $20 \mu \mathrm{M}$ substrates in citrate-phosphate buffer $(\mathrm{pH}$ 6.5). A $15-\mu l$ aliquot was taken at different time points and heated at $95^{\circ} \mathrm{C}$ for $10 \mathrm{~min}$. The hydrolysate profiles were analyzed on a Silica Gel 60 TLC plate (Merck, Darmstadt, Germany) using 
a solution of $n$-butanol/acetic acid/water $(10: 5: 1, \mathrm{v} / \mathrm{v})$ as the solvent. Spots were visualized by spraying with staining solution $\left[0.5 \%\right.$ sulfuric acid in methanol (v/v)] and heating at $115^{\circ} \mathrm{C}$ for 5 min. A mixture of XOSs (X1-X6) was used as the standard.

\section{RESULTS}

\section{Sequence and Structural Analysis of XynSPP2}

Marinifilaceae bacterium strain SPP2 is a recently isolated polar microorganism classified into the family Marinifilaceae (Watanabe et al., 2018). Less commonly, as a Gram-negative bacterium, it encodes several predicted xylantic enzymes. $\mathrm{XynSPP} 2$ is one of the enzyme encoded by an open reading frame of $1353 \mathrm{bp}$ (450 amino acid residues). The theoretical molecular mass and deduced isoelectric point of XynSPP2 are 50,461.40 $\mathrm{Da}$ and 4.87, respectively. A 24-residue signal peptide is present at the amino-terminus of protein as predicted by SignalP 5.0 $(D=0.712, D$-cutoff $=0.570)$. The signal peptide is followed by an Fn3 domain and a GH10 domain as indicated by analysis using the Conserved Domain Search.

BLASTp search indicated that XynSPP2 was mostly identical (84\%) to putative $\beta$-1,4-xylanase from Labilibaculum filiforme (GenBank accession number: WP_101261729.1), which has the same domain arrangement. The Fn3 and GH10 domains in XynSPP2 also shared the highest identities (73 and 91\%) to those from $L$. filiforme xylanase, respectively. The second most identical sequence was hypothetical protein from Saccharicrinis fermentans (GenBank accession number: WP_044212766.1), which is $55 \%$ identical to XynSPP2. Amino acid sequence alignment showed that XynSPP2 was $17-46 \%$ identical to those characterized GH10 xylanases collected in the CAZy database (320 sequences of characterized GH10 xylanases). Among the characterized GH10 xylanases, XynSPP2 showed the highest sequence identity $(46 \%)$ to the xylanase from Flavobacterium johnsoniae UW101 (GenBank accession number: ABQ06877.1). The GH10 domain of XynSPP2 was also mostly identical to that of F. johnsoniae UW101 xylanase, with 49\% sequence identity (Supplementary Figure S1). Multiple sequence alignment also revealed the putative catalytic residues (acid/base catalyst: Glu256; nucleophile: Glu363) and amino acids involved in substrate binding (Glu170, Trp171, Lys174, His207, Ser214, Asn255, Trp300, Gln332, His334, and Trp410) in XynSPP2 (Figure 1 and Supplementary Figure S2). The latter were largely conserved in XynSPP2 except two variations at the $-2 /-3$ subsite (Figure 1 and Supplementary Figure S2). The conserved asparagine and glutamine at $-2 /-3$ in GH10 xylanases are replaced for tryptophan (Trp171) and serine (Ser214), respectively (Figure 1). These two natural variations are also present in the putative GH10 xylanase from L. filiforme.

Due to the absence of a model template for full-length XynSPP2 in PDB, the crystal structure of the GH10 domain of CjXyn10C (PDB entry: 1US3) and crystal structure of the Fn3 domain from human Contactin (PDB entry: 4N68) were used as the templates to generate model structures of the Fn3 and GH10 domains in XynSPP2, respectively. The amino acid similarity between the GH10 domains of XynSPP2 and CjXyn10C is 56\% (35\% identity), and the similarity between the Fn3 domains of XynSPP2 and human Contactin is $41 \%$ (24\% identity). The qualities of both modeled structures were acceptable as indicated by the good QMEAN Z-score (Benkert et al., 2011) (2.18 for the GH10 domain and 3.83 for the Fn3 domain) from the SWISS-MODEL server pipeline and excellent structure validation statistics by MolProbity (MolProbity score: $1.81,85^{\text {th }}$ percentile). All amino acids situated in the substratebinding cleft showed a reliable geometry (allowable torsion angles and no steric problem). A structural model of intact XynSPP2 was obtained by assembling the two domains manually (Figure 2). The resulting structure indicated that the GH10 domain of XynSPP2 exhibits a typical $(\beta / \alpha)_{8}$-barrel of GH10 xylanases composed of alternating $\alpha$-helices and $\beta$-strands. The

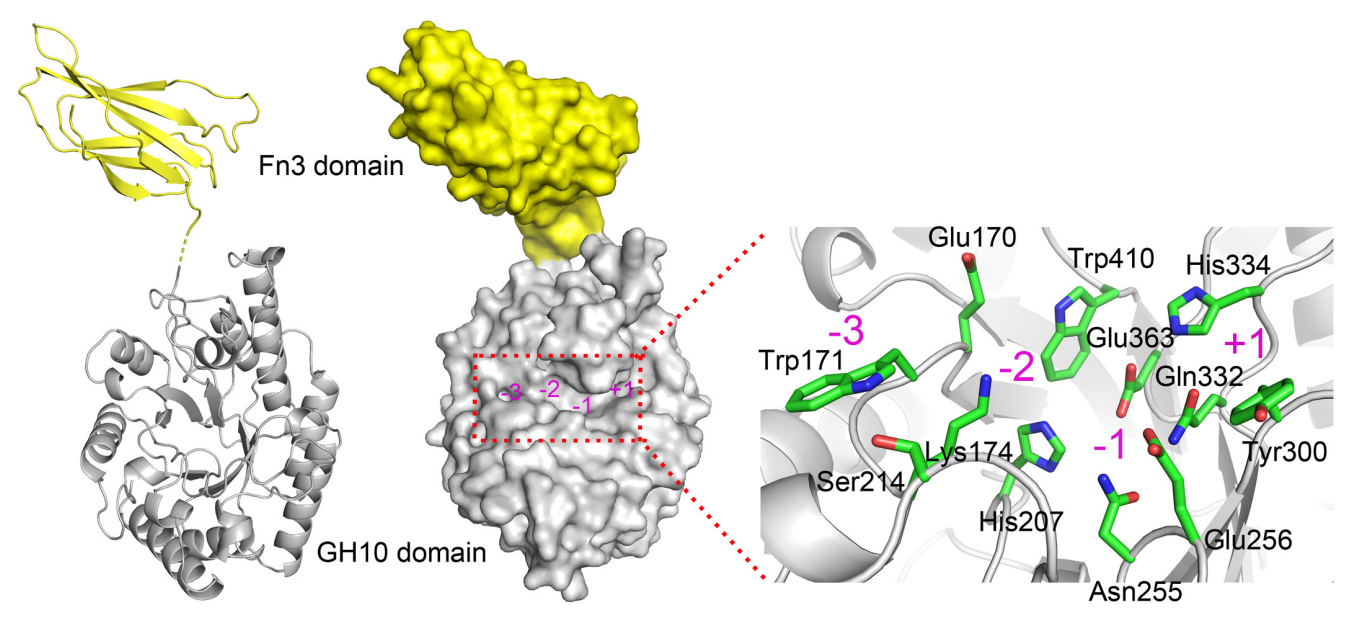

FIGURE 2 | Predicted 3-D structure of XynSPP2. XynSPP2 consists of an N-terminal Fn3 domain (yellow) and a C-terminal GH10 domain (gray). Overall structural architecture of XynSPP2 is presented as cartoon (left) and surface (middle) models. Amino acids constituting the active-site cleft of XynSPP2 are shown in green stick (right). Subsites in the active-site cleft are indicated by magenta numbers. 
Fn3 domain shows the conserved $\beta$-sandwich fold consisting of two beta sheets (one containing four strands and the other sheet containing three strands) (Figure 2). Trp171 and Ser214 comprise the distal edge of -2 subsite $(-2 /-3)$ (Figure 2$)$, which agrees with the prediction from multiple amino acid sequence alignment (Figure 1).

\section{Expression and Purification of Recombinant XynSPP2 and XynSPP2 $\Delta$ Fn3}

Recombinant XynSPP2 (amino acid residues 25-450) and XynSPP2 $\triangle$ Fn3 (amino acid residues 137-450) were produced using the $E$. coli system and purified by Ni-affinity chromatography. Both recombinant proteins had a polypeptide of 34 amino acids from the pET-28a vector on their N-terminals and were purified to electrophoretic homogeneity (Figure 3). The purified XynSPP2 and XynSPP2 $\Delta$ Fn3 exhibited a single band with molecular masses that corresponded to their

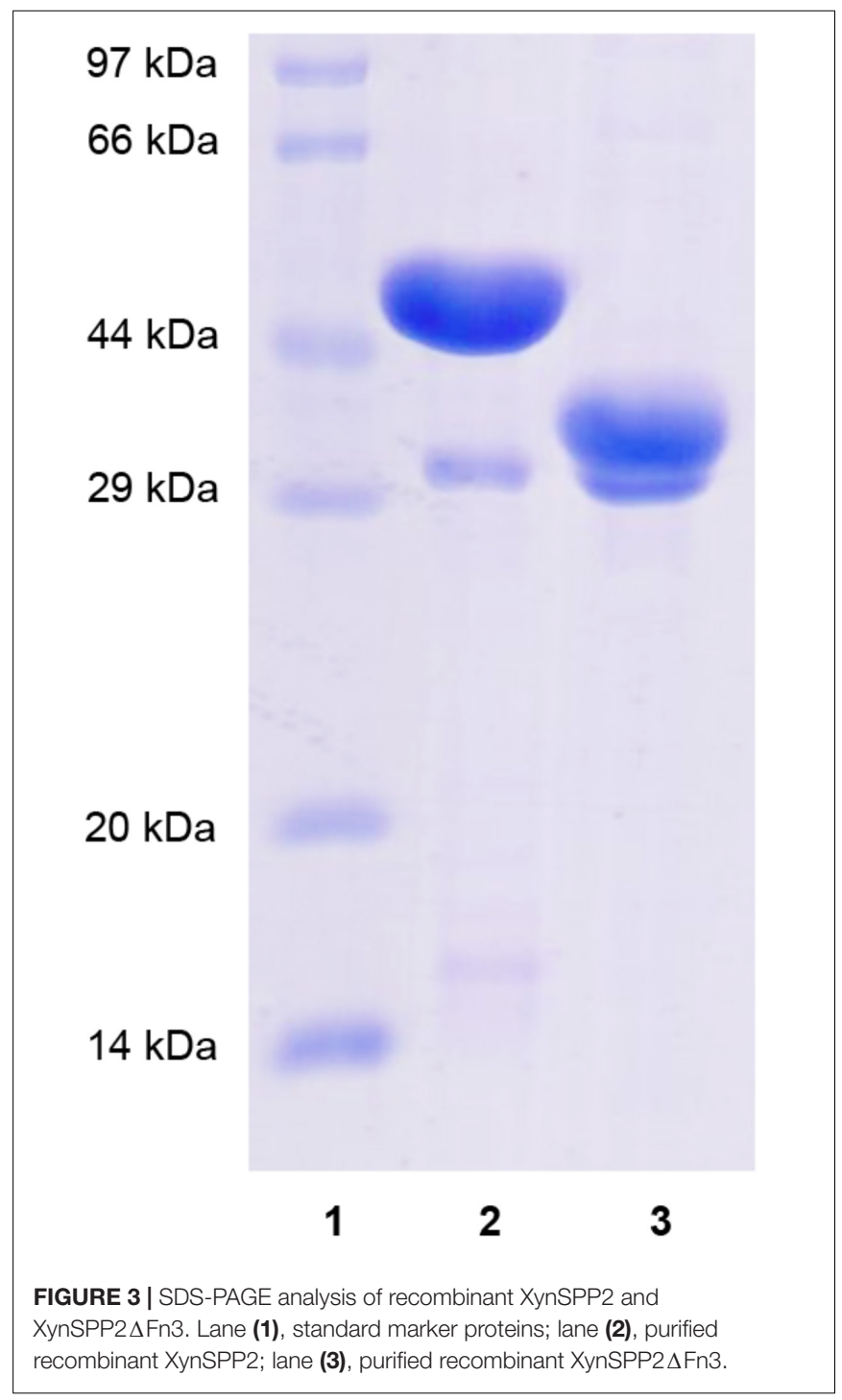

calculated values of $51,364.15$ and $39,244.76 \mathrm{Da}$, as shown in SDS-PAGE (Figure 3).

\section{Biochemical Properties of XynSPP2 and XynSPP2 $\Delta$ Fn3}

The xylanase activity of XynSPP2 or XynSPP $2 \Delta \mathrm{Fn} 3$ was tested on $\beta$-1,4-linked xylose polysaccharide beechwood xylan. Both recombinant enzymes had similar $\mathrm{pH}$ and temperature profiles and exhibited a $\mathrm{pH}$ optima of 6 (Figure 4A) and temperature optima of $50^{\circ} \mathrm{C}$ (Figure 4B). XynSPP2 retained approximately $60 \%$ maximum activity over $\mathrm{pH} 5-9$ and at least $40 \%$ maximum activity at $30^{\circ} \mathrm{C}-50^{\circ} \mathrm{C}$. Compared with fulllength XynSPP2, XynSPP2 $\Delta$ Fn3 was active across a narrower $\mathrm{pH}$ range (in particular of alkaline range) and a broader temperature range.

Both XynSPP2 and XynSPP2 $\triangle$ Fn3 were stable above $\mathrm{pH} 4$, retaining more than $80 \%$ of the maximum activity (Figure $4 \mathrm{C}$ ). Deletion of the Fn3 domain almost did not affect the thermal stability of XynSPP2, as demonstrated by the nearly complete loss of their activity after incubation at $50^{\circ} \mathrm{C}$ for $1 \mathrm{~h}$ (Figure 4D).

All of the tested divalent cations $\left(\mathrm{Co}^{2+}, \mathrm{Ca}^{2+}, \mathrm{Fe}^{2+}, \mathrm{Mg}^{2+}\right.$, $\mathrm{Mn}^{2+}, \mathrm{Ni}^{2+}$, and $\mathrm{Zn}^{2+}$ ) at $5 \mathrm{mM}$ suppressed the activity of XynSPP2 by different degrees (ranging from 6 to 28\%) relative to its original activity. Among them, the negative effect of $\mathrm{Fe}^{2+}$ was the most potent (Figure 5A). The activity of XynSPP2 increased by approximately $5 \%$ in the presence of EDTA. Reducing reagents, DTT $(10 \mathrm{mM})$ and $\beta$-mercaptoethanol $(10 \mathrm{mM})$, inhibited the activity of XynSPP2 by 15 and $20 \%$, respectively. Anionic detergent SDS (10 mM, approximately $0.3 \%)$ and nonionic surfactant Triton X-100 (0.5\%) showed the reverse effect, retaining 55 and $113 \%$ xylanase activities, respectively. In the presence $5 \%$ of organic solvents, ethanol, methanol, isopropanol, and glycerol, XynSPP2 retained approximately 30\% relative activity. The activity of XynSPP2 was completely inhibited in the presence of $5 \% n$-butanol. The other tested organic solvents acetone and DMSO at $10 \%$ showed inhibitory effect. When the xylanase reactions were conducted in the presence of ammonium sulfate, urea, or $\mathrm{GuHCl}$ at a concentration of $100 \mathrm{mM}$, XynSPP2 showed 95,110 , and $65 \%$ of its original activity, respectively.

XynSPP2 was halophilic as demonstrated by greatly enhanced xylanase activity with the addition of a certain amount of $\mathrm{NaCl}$ in the reaction mixtures (Figure 5B). When the reactions were performed in the presence of $\mathrm{NaCl}$ at concentrations ranging from 0.5 to $2.5 \mathrm{M}$, XynSPP2 exhibited more than $210 \%$ of its original activity.

The whole enzyme XynSPP2 had a $K_{m}$ value of $0.97 \mathrm{mg} / \mathrm{ml}$ for beechwood xylan (Table 1 and Supplementary Figure S3). The absence of the Fn3 domain led to a $K_{m}$ value of 1.81 times that of intact XynSPP2. The $k_{\text {cat }}$ values of XynSPP2 and XynSPP2 $\Delta$ Fn3 were 178.19 and $117.27 \mathrm{~s}^{-1}$, respectively. The catalytic efficiency (as measured by $k_{\text {cat }} / K_{m}$ ) of XynSPP $2 \Delta$ Fn3 was approximately one third that of XynSPP2.

\section{Hydrolytic Properties of XynSPP2}

Hydrolytic properties of XynSPP2 were investigated with XOSs and beechwood xylan using the whole enzyme XynSPP2. No 

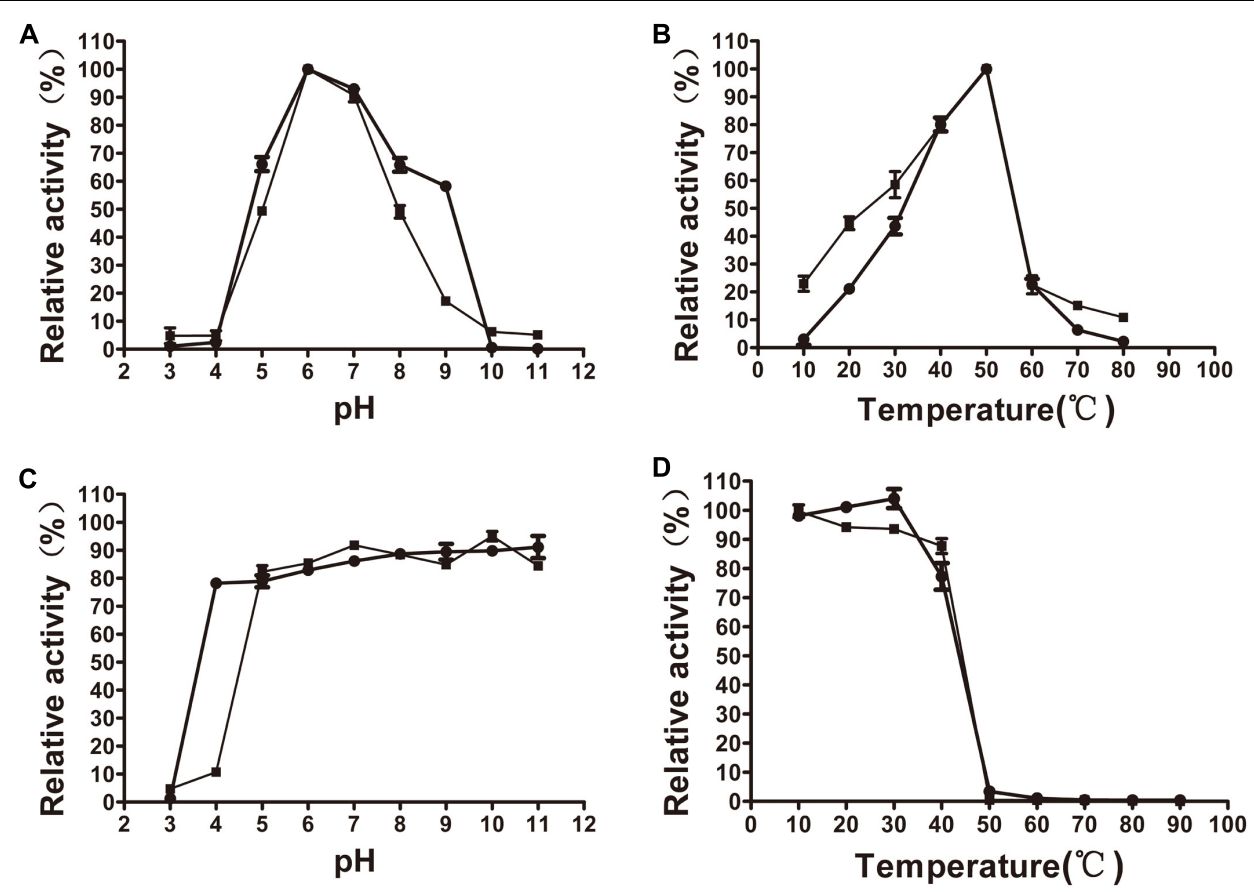

FIGURE 4 | Effects of pH and temperature on the activity and stability of recombinant XynSPP2 $\Delta$ Fn3 (blank squares) and XynSPP2 (blank dots). (A) Optimal pH of XynSPP2 $\Delta$ Fn3 and XynSPP2. (B) Optimal temperatures of XynSPP2 $\Delta$ Fn3 and XynSPP2. (C) pH stability of XynSPP2 $\Delta$ Fn3 and XynSPP2. (D) Thermal stability of XynSPP2 $\triangle \mathrm{Fn} 3$ and XynSPP2.

detectable activity toward xylobiose was observed (Figure 6). Only a small amount of xylotriose was hydrolyzed by XynSPP2 after $8 \mathrm{~h}$ of incubation. XynSPP2 hydrolyzed xylotetraose to xylotriose (major) and xylobiose. Degradations of xylopentaose and xylohexaose by XynSPP2 were largely similar, with xylotetraose, xylotriose, and xylobiose as the intermediate enzymatic products and with xylotriose and xylobiose as the final products. The product patterns of beechwood xylan by XynSPP2 after the different incubation periods (1, 2, 4, and $8 \mathrm{~h}$ ) were nearly similar, with xylotetraose and xylotriose as the major products. No monosaccharide was detected in the enzymatic products of the above substrates (Figure 6).

\section{DISCUSSION}

To date, a large number of GH10 xylanases from bacteria and fungi have been cloned and biochemically characterized (Linares-Pasten et al., 2018). Similar to many other glycoside hydrolases, many xylanases have one or more accessory domains appended to the GH10 catalytic domain through short junction segments (Collins et al., 2005; Talamantes et al., 2016). These auxiliary domains, including carbohydrate-binding modules (CBMs) (Carvalho et al., 2015), dockerin domain (Khan et al., 2013), C-terminal ricin-type $\beta$-trefoil lectin domain-like domain (Kim et al., 2018), Fn3 domain (Kim et al., 2009; Chen et al., 2013; Sermsathanaswadi et al., 2017), and S-layer homology domains (Zhao et al., 2013; Lee and Lee, 2014), are noncatalytic, but potentiate the activity of xylanases (Guillén et al.,
2010; Sakka et al., 2011) and promote the thermal stability (Kim et al., 2000, 2016) and pH stability (Li et al., 2009; Kim et al., 2016) of the enzymes.

Among the functionally characterized xylanases, only few carry the Fn3 domain (Kim et al., 2009; Chen et al., 2013; Sermsathanaswadi et al., 2017), even though it frequently exists in many other GHs such as cellulases and chitinases. The Fn3 module is important for the catalytic ability of xylanases. Removing the Fn3 domain considerably decreases xylanolytic activity of xylK1 from Cellulosimicrobium sp. strain HY-13 (Kim et al., 2009) and Xyn10A from Flavobacterium johnsoniae (Chen et al., 2013). However, the specific function of the Fn3 domain in xylanases has yet to be investigated. A previous study proposed that the Fn3 domains in GHs enhance hydrolysis by eroding the surface of large polymeric carbohydrate substrates (Kataeva et al., 2002), being directly involved in binding to the soluble substrate, or being served as linkers synergizing interaction between CBMs and polymeric substrate (Watanabe et al., 1994; Chen et al., 2013). No other accessory domains are fused to XynSPP2 except for the Fn3 domain. Therefore, the Fn3 domain in XynSPP2 likely potentiates the activity of the enzymes by strengthening the binding of the GH10 domain to beechwood xylan, as evidenced by the lower $K_{m}$ value for XynSPP2 than for XynSPP2 $\Delta$ Fn3.

Amino acid sequence comparison indicated that XynSPP2 is highly identical (84\%) to an uncharacterized GH10 xylanase from $L$. filiforme but shares relatively low sequence identity to characterized GH10 xylanases (17-46\%). XynSPP2 identified from Marinifilaceae bacterium SPP2 was originally isolated from the Antarctic marine sediment (Watanabe et al., 2018). 


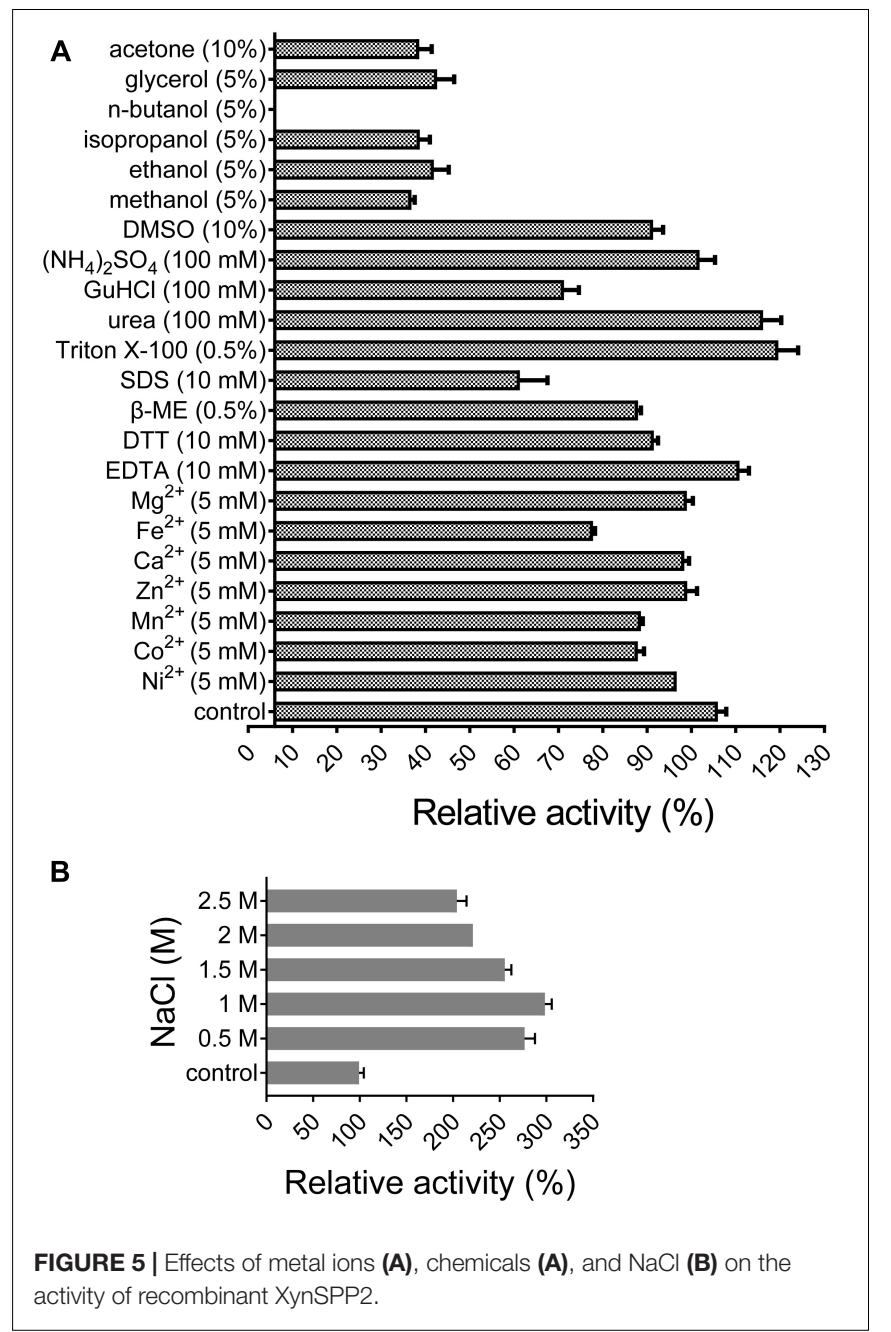

However, the recombinant XynSPP2 showed a temperature optimum of $50^{\circ} \mathrm{C}$ (Figure 4), which is much higher than the living temperature of its host bacterium $\left(0-25^{\circ} \mathrm{C}\right)$ (Watanabe et al., 2018) and the average temperature of Antarctic marine environment (normally approximately $1^{\circ} \mathrm{C}$ ) (Marx et al., 2007). XynSPP2 only showed approximately $20 \%$ optimal activity at $20^{\circ} \mathrm{C}$ and was completely inactive at temperatures below $10^{\circ} \mathrm{C}$ (Figure 4). The temperature property of XynSPP2 does not resemble those of cold-active enzymes mostly obtained from psychrophilic or psychrotolerant organisms that normally retain large portion of their optimal activities (Santiago et al., 2016). The only feature of XynSPP2 similar to cold-active enzymes is its thermal instability. XynSPP2 is thermolabile because it was unstable at temperatures above $40^{\circ} \mathrm{C}$ (Figure 4 and Table 2). These temperature properties imply that XynSPP2 has not or incompletely adapted to cold environments during evolution.

The activity of XynSPP2 was suppressed in the presence of many divalent cations $\left(\mathrm{Co}^{2+}, \mathrm{Ca}^{2+}, \mathrm{Fe}^{2+}, \mathrm{Mg}^{2+}, \mathrm{Mn}^{2+}\right.$, $\mathrm{Ni}^{2+}$, and $\mathrm{Zn}^{2+}$ ) at a concentration of $5 \mathrm{mM}$ (Figure 5). Similar results were observed in Xyn10A from Bacillus sp. SN5 (Bai et al., 2012) and xyl-gt from Geobacillus thermoleovorans
TABLE 1 | Kinetic parameters of XynSPP2 and XynSPP2 $\triangle$ Fn3.

\begin{tabular}{lcccc}
\hline Enzyme & $\boldsymbol{V}_{\boldsymbol{m a x}}(\mathbf{U} / \mathbf{m g})$ & $\boldsymbol{K}_{\boldsymbol{m}}(\mathbf{m g} / \mathbf{m l})$ & $\boldsymbol{k}_{\text {cat }}\left(\mathbf{s}^{-1}\right)$ & $\begin{array}{c}\boldsymbol{k}_{\text {cat }} / \boldsymbol{K}_{\boldsymbol{m}} \\
(\mathbf{m l} / \mathbf{s} / \mathbf{m g})\end{array}$ \\
\hline XynSPP2 & 226.56 & 0.97 & 178.19 & 183.70 \\
XynSPP2 $\Delta$ Fn3 & 176.55 & 1.76 & 117.27 & 66.63 \\
\hline
\end{tabular}

(Verma and Satyanarayana, 2012; Table 2). By contrast, the xylanase activities of many GH10 xylanases can be improved by adding a certain metal ion, such as Xyn10A from F. johnsoniae by $\mathrm{Mn}^{2+}$ (Chen et al., 2013), xylK1 (Kim et al., 2009) by $\mathrm{Fe}^{2+}$, xynAHJ2 from Bacillus sp. HJ2 by $\mathrm{Mg}^{2+}$ (Zhou et al., 2012), XynA from Sorangium cellulosum (Wang et al., 2012) by $\mathrm{Ca}^{2+}$ and $\mathrm{Mg}^{2+}$, and XylC from Cohnella laeviribosi HY-21 by $\mathrm{Ni}^{2+}$ and $\mathrm{Mn}^{2+}$ (Kim et al., 2010). The activity of XynSPP2 was inhibited by EDTA $(5 \mathrm{mM})$. Similar adverse effects of EDTA have been reported for the most tested GH10 xylanases, including XylC (C. laeviribosi HY-21) (Kim et al., 2010), xylgt (Verma and Satyanarayana, 2012), Xyn10A from Bacillus sp. SN5 (Bai et al., 2012), XynA from S. cellulosum (Wang et al., 2012), Xyn10A from F. johnsoniae (Chen et al., 2013), and XylK1 (Kim et al., 2009). The positive effects of EDTA on GH10 xylanases have been observed for XynA from Glaciecola mesophila KMM 241 (Guo et al., 2009) and xynAHJ2 from Bacillus sp. (Zhou et al., 2012). Reducing reagents DTT and $\beta$-mercaptoethanol (both at $10 \mathrm{mM}$ ) suppressed the activity of XynSPP2 by $15-20 \%$, similar to that observed for xylgt (Verma and Satyanarayana, 2012). Anionic detergent SDS normally showed inhibitory effects on xylanase activity. In the presence of SDS at $10 \mathrm{mM}$, the activity of XynSPP2 reduced by $45 \%$. XynSPP2 was more susceptible to SDS than Xyn10A from Bacillus sp. SN5 (5 mM, 55\% residual activity) (Bai et al., 2012) and Xyn10A from F. johnsoniae (17 mM, 64\% residual activity) (Chen et al., 2013), but the SDS tolerance of XynSPP2 was much higher than that of XynA from S. cellulosum $(10 \mathrm{mM}$, $0.5 \%$ residual activity) (Wang et al., 2012) and XynA from G. mesophila KMM 241 (10 mM, 0\% residual activity) (Guo et al., 2009). Non-ionic surfactant Triton-X 100 (0.5\%) improved the activity of XynSPP2 by $13 \%$. The activity promotion of XynSPP2 by Triton X-100 was comparable to that of Xyn10A from $F$. johnsoniae $(0.5 \%, 114 \%$ residual activity) (Chen et al., 2013) but was weaker than that of XylC from C. laeviribosi HY$21(0.5 \%, 222 \%$ residual activity) (Kim et al., 2010) and XylK1 (0.5\%, 180\% residual activity) (Kim et al., 2009). XynSPP2 was more susceptible to the tested organic solvents at 5\%, compared with xyl-gt (Verma and Satyanarayana, 2012), Xyn10A from Bacillus sp. SN5 (Bai et al., 2012), and Xyn10A from F. johnsoniae (Chen et al., 2013).

In general, the hydrolytic product patterns of xylanases are dependent on the interactions between subsites and xylose residues in the active-site cleft. Without considering the effect of heteroxylan structure, the subsite topology and composition determine the positional binding and cleavage (Schmidt et al., 1999; Pollet et al., 2010; Linares-Pasten et al., 2018). Structural studies have shown that the glycone subsites of GH10 xylanases are highly conserved on the whole and 


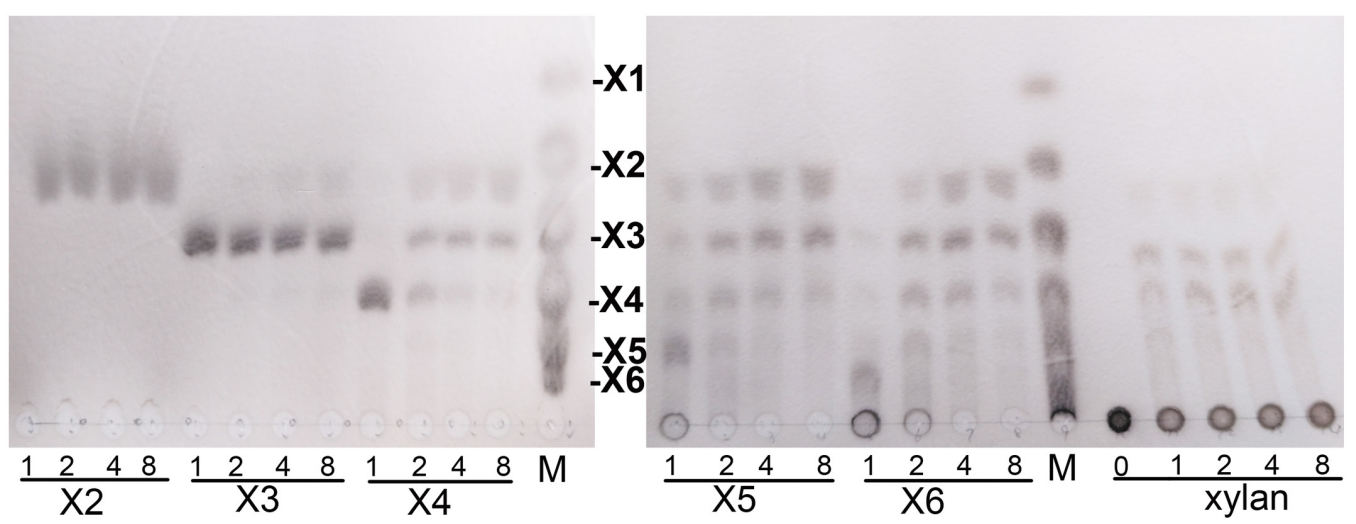

FIGURE 6 | Thin-layer chromatography analysis of XynSPP2-catalyzed products of XOSs and beechwood xylan. XOS standards: X1, xylose; X2, xylobiose; X3, xylotriose; X4, xylotetraose; X5, xylopentaose; and X6, xylohexaose.

TABLE 2 | Biochemical characteristics of characterized GH10 xylanases.

\begin{tabular}{|c|c|c|c|c|c|c|}
\hline $\begin{array}{l}\text { Xylanase (source } \\
\text { microorganism) }\end{array}$ & $\mathrm{T}_{\text {opt }} \mathrm{pH}_{\mathrm{opt}}$ & $\begin{array}{l}\text { pH stability (residual } \\
\text { activity) }\end{array}$ & $\begin{array}{l}\text { Thermal } \\
\text { stability } \\
\text { (residual } \\
\text { activity) }\end{array}$ & $\begin{array}{l}\text { Kinetic values } \\
\text { (temperature) } \\
\text { (substrate) }\end{array}$ & $\begin{array}{l}\text { Hydrolysis } \\
\text { products } \\
\text { (substrate) }\end{array}$ & $\begin{array}{l}\text { Reference and } \\
\text { sequence } \\
\text { accession } \\
\text { number }\end{array}$ \\
\hline $\begin{array}{l}\text { XynSPP2 } \\
\text { (Marinifilaceae } \\
\text { bacterium SPP2) }\end{array}$ & $50^{\circ} \mathrm{C}, \mathrm{pH} 6$ & $80 \%, \mathrm{pH} 4-11,1 \mathrm{~h}$ & $88 \%, 40^{\circ} \mathrm{C}, 1 \mathrm{~h}$ & $\begin{array}{l}K_{m}: 0.97 \mathrm{mg} / \mathrm{ml} \\
k_{\text {cat }}: 178.19 \mathrm{~s}^{-1}\left(50^{\circ} \mathrm{C}\right) \\
\text { (beechwood xylan) }\end{array}$ & $\begin{array}{l}\text { X2, X3, X4 } \\
\text { (beechwood xylan) }\end{array}$ & $\begin{array}{l}\text { This work } \\
\text { WP_096428726.1 }\end{array}$ \\
\hline $\begin{array}{l}\text { xylK1 } \\
\text { (Cellulosimicrobium sp. } \\
\text { strain HY-13) }\end{array}$ & $55^{\circ} \mathrm{C}, \mathrm{pH} 6$ & & $\begin{array}{l}50 \%, 55^{\circ} \mathrm{C} \\
20 \mathrm{~min}\end{array}$ & & $\begin{array}{l}\text { X2, X3, X4 } \\
\text { (Birchwood xylan) }\end{array}$ & $\begin{array}{l}\text { Kim et al., } 2009 \\
\text { FJ859907 }\end{array}$ \\
\hline $\begin{array}{l}\text { Xyn10A } \\
\text { (Flavobacterium } \\
\text { johnsoniae) }\end{array}$ & $30^{\circ} \mathrm{C}, \mathrm{pH} 8$ & $55 \%, \mathrm{pH} 5-9,1 \mathrm{~h}$ & $50 \%, 40^{\circ} \mathrm{C}, 2 \mathrm{~h}$ & $\begin{array}{l}K_{m}: 5 \mathrm{mg} / \mathrm{ml}, \\
k_{\text {cat }}: 10.7 \mathrm{~s}^{-1}\left(35^{\circ} \mathrm{C}\right) \\
\text { (beechwood xylan) }\end{array}$ & $\begin{array}{l}\text { X1, X2, X3 } \\
\text { (beechwood xylan) }\end{array}$ & $\begin{array}{l}\text { Chen et al., } 2013 \\
\text { YP_001196196 }\end{array}$ \\
\hline $\begin{array}{l}\text { Xyn10A (Bacillus sp. } \\
\text { SN5) }\end{array}$ & $40^{\circ} \mathrm{C}, \mathrm{pH} 7$ & $80 \%, \mathrm{pH} 5.5-9.9,24 \mathrm{~h}$ & $\begin{array}{l}48 \%, 40^{\circ} \mathrm{C} \\
30 \min \end{array}$ & $\begin{array}{l}K_{m}: 0.6 \mathrm{mg} / \mathrm{ml}, \\
k_{\text {cat }}: 85.4 \mathrm{~s}^{-1}\left(40^{\circ} \mathrm{C}\right) \\
\text { (beechwood xylan) }\end{array}$ & & $\begin{array}{l}\text { Bai et al., } 2012 \\
\text { AGA16736.1 }\end{array}$ \\
\hline $\begin{array}{l}\text { xyl-gt (Geobacillus } \\
\text { thermoleovorans) }\end{array}$ & $70^{\circ} \mathrm{C}, \mathrm{pH} 9$ & $90 \%, \mathrm{pH} 8-10,3 \mathrm{~h}$ & $\begin{array}{l}50 \%, 80^{\circ} \mathrm{C} \\
10 \min \end{array}$ & $\begin{array}{l}K_{m}: 0.63 \mathrm{mg} / \mathrm{ml},\left(70^{\circ} \mathrm{C}\right) \\
\text { (birchwood xylan) }\end{array}$ & $\begin{array}{l}\text { X1, XOS } \\
\text { (birchwood xylan) }\end{array}$ & $\begin{array}{l}\text { Verma and } \\
\text { Satyanarayana, } \\
2012 \text { AFU93447.1 }\end{array}$ \\
\hline $\begin{array}{l}\text { xynAHJ2 (Bacillus sp. } \\
\text { HJ2) }\end{array}$ & $\begin{array}{l}35^{\circ} \mathrm{C}, \mathrm{pH} \\
6.5\end{array}$ & $50 \%, \mathrm{pH} 6-10,1 \mathrm{~h}$ & $\begin{array}{l}50 \%, \geq 45^{\circ} \mathrm{C} \\
5 \min \end{array}$ & $\begin{array}{l}K_{m}: 0.5 \mathrm{mg} / \mathrm{ml}, \\
K_{\text {cat }}: 11.9 \mathrm{~s}^{-1}\left(35^{\circ} \mathrm{C}\right) \\
\text { (birchwood xylan) }\end{array}$ & & $\begin{array}{l}\text { Zhou et al., } 2012 \\
\text { AFE82288.1 }\end{array}$ \\
\hline $\begin{array}{l}\text { XynA (Sorangium } \\
\text { cellulosum So9733-1) }\end{array}$ & $\begin{array}{l}30-35^{\circ} \mathrm{C} \\
\mathrm{pH} 7\end{array}$ & $60 \%, \mathrm{pH} 6-9,1 \mathrm{~h}$ & $\begin{array}{l}20 \%, 50^{\circ} \mathrm{C} \\
20 \min \end{array}$ & $\begin{array}{l}K_{m}: 25.8 \mathrm{mg} / \mathrm{ml}, \\
k_{\text {cat }}: 6.8 \mathrm{~s}^{-1}\left(30^{\circ} \mathrm{C}\right) \\
\text { (beechwood xylan) }\end{array}$ & $\begin{array}{l}\text { X1, X2 } \\
\text { (beechwood xylan) }\end{array}$ & $\begin{array}{l}\text { Wang et al., } 2012 \\
\text { AEB69780.1 }\end{array}$ \\
\hline $\begin{array}{l}\text { XylC (Cohnella } \\
\text { laeviribosi HY-21) }\end{array}$ & $\begin{array}{l}50^{\circ} \mathrm{C}, \mathrm{pH} \\
7.5\end{array}$ & & $\begin{array}{l}50 \%, 50^{\circ} \mathrm{C} \\
15 \min \end{array}$ & & & $\begin{array}{l}\text { Kim et al., } 2010 \\
\text { EDV78425 }\end{array}$ \\
\hline $\begin{array}{l}\text { XynA (Glaciecola } \\
\text { mesophila KMM241) }\end{array}$ & $30^{\circ} \mathrm{C}, \mathrm{pH} 7$ & $80 \%, \mathrm{pH} 6-8,1 \mathrm{~h}$ & $20 \%, 30^{\circ} \mathrm{C}, 1 \mathrm{~h}$ & $\begin{array}{l}K_{m}: 1.22 \mathrm{mg} / \mathrm{ml} \\
k_{\text {cat }}: 69 \mathrm{~s}^{-1}\left(30^{\circ} \mathrm{C}\right) \\
\text { (beechwood xylan) }\end{array}$ & $\begin{array}{l}\text { X2, X3 } \\
\text { (beechwood xylan) }\end{array}$ & $\begin{array}{l}\text { Guo et al., } 2009 \\
\text { ACN76857.1 }\end{array}$ \\
\hline
\end{tabular}

crucial for substrate binding (Pollet et al., 2010). Structural comparison of XynSPP2 with other GH10 xylanases revealed that XynSPP2 had an unusual amino acid composition at glycone subsites (Figures 1, 2, 7). Two conserved amino acid residues (asparagine and glutamine), as the constituent part of the $-2 / 3$ subsite (in the distal region of -2 subsite $(-2 / 3)$ and form important hydrogen bonds with $\mathrm{O} 3$ and $\mathrm{O} 5$ in -2 xylose residue) of the GH10 xylanases, are substituted by a tryptophan and an asparagine in XynSPP2 (Figure 7). It has been for example showed that natural variation (Glu/Gly substitution) (Figure 7) at the $-2 /-3$ subsite of CjXyn10C weakens the affinity for XOSs (X3-X6) (10-100-fold lower) but not xylan (Pell et al., 2004). Another variation at the $-2 /-3$ subsite of CjXyn10C changes the cleavage pattern of the enzyme (Pell et al., 2004). Inserting tyrosine residue (Tyr340) at the $-2 /-3$ subsite established a strong -3 subsite through forming stacking interaction with -3 xylose residue (Figure 7 ). With this tyrosine residue, the enzyme becomes more inclined to 


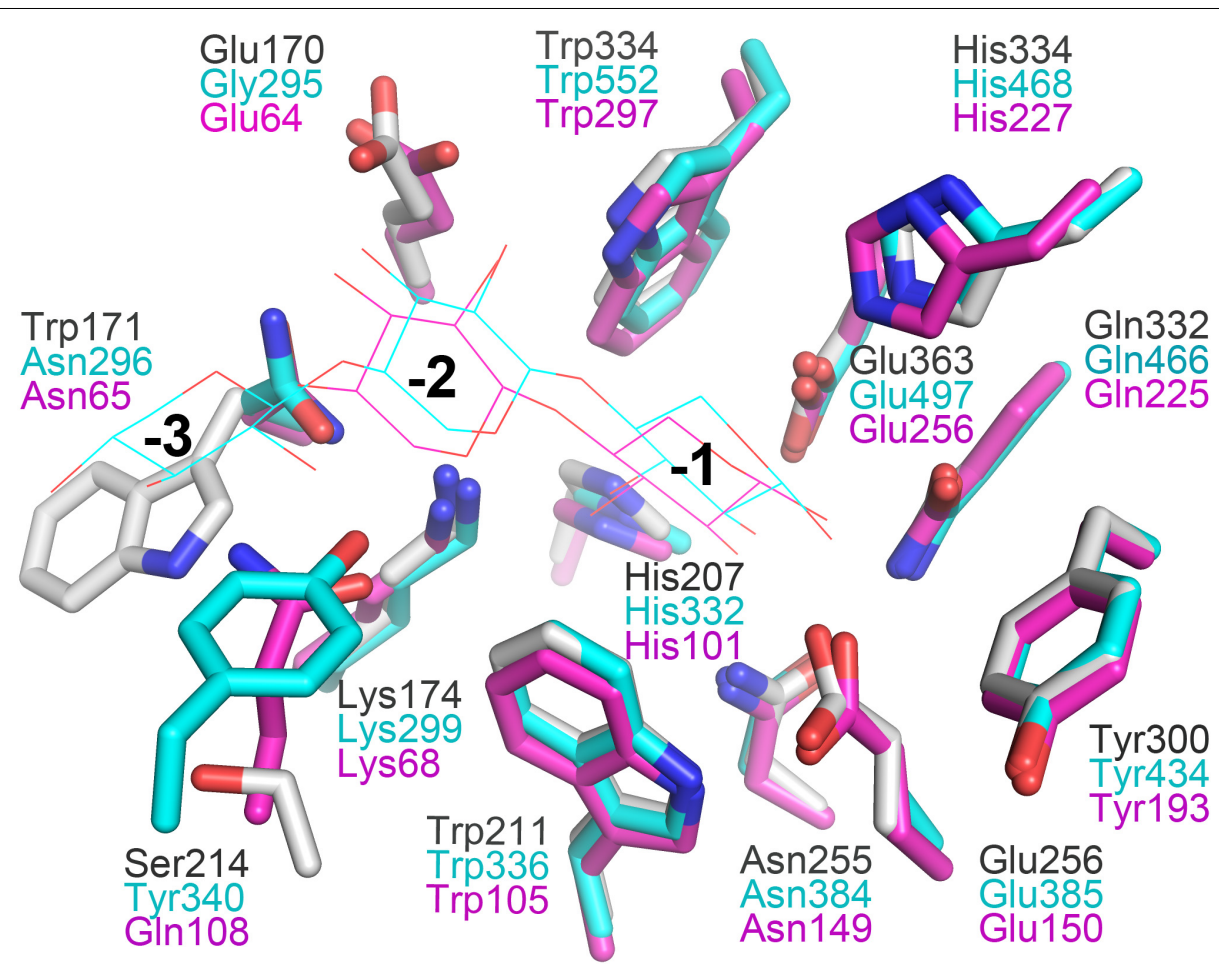

FIGURE 7 | Superimposition of the subsites of XynSPP2 (gray), CjXyn10C (xylanase from Cellvibrio japonicas in complex with xylotriose, PDB entry:1US2, cyan), and TpXyl10B (xylanase from Thermotoga petrophila RKU-1 in complex with xylobiose, PDB entry: 3NJ3, magenta). The amino acid and xylose residues are shown in stick and line models, respectively.

cleave the terminal glyosidic bond of xylotetraose rather than to act in a symmetric cleavage manner (Pell et al., 2004). Trp171, one of the two variant amino acids in the activesite cleft of XynSPP2, has similar position and biochemical property to Tyr340. Therefore, we speculate that aromatic Trp171 in XynSPP2 possibly forms a strong -3 subsite for xylose binding as Tyr340 in CjXyn10C (Pell et al., 2004). Accordingly, a similar substrate-binding mode as for CjXyn10C may be adopted by XynSPP2.

Due to the strong and specific binding at the glycone subsites ( -2 to -1 or -3 to -1 when -3 subsite exists), the number of strong glycone subsites in the active-site cleft has been proposed to be the determinant for the minimum size of XOSs as substrates for effective hydrolysis (Schmidt et al., 1999; Linares-Pasten et al., 2018; Nordberg Karlsson et al., 2018). Therefore, the presence of a putative strong -3 subsite in XynSPP2 suggested that XOSs longer than xylotriose can be effectively cleaved by the enzyme, as evidenced by our TLC experiment. The TLC results indicated that the shortest substrate that was effectively cleaved by XynSPP2 is xylotetraose (Figure 6). With xylotetraose as the substrate, xylotriose predominantly appeared in the intermediate sample $(2 \mathrm{~h})$, suggesting that xylotetraose was more frequently cleaved into xylotriose and xylose, although a -2 to +2 cleavage also occurred. Digestion of xylopentaose yielded mainly xylotriose and xylobiose. According to the architecture of the glycone subsites in XynSPP2 and the product patterns of XOSs, we can speculate that the enzyme had at least four subsites to be filled for substantial activity. Xylotetraose mainly occupied subsites -3 to +1 and xylopentaose predominantly bound at -3 to +2 subsites. Short XOSs (xylobiose and xylotriose) were not easily hydrolyzed by XynSPP2 because the whole molecules bound to the glycone subsites. Notably, no detectable xylose was observed in all hydrolysis samples which was probably ascribed to a transxylosylation reaction catalyzed by XynSPP2. The released xylose molecules were transferred to the covalent xylosyl-enzyme intermediate, generating long XOSs such as xylotetraose or xylopentaose. The lack of xylose in the degradation product of XOSs was also observed for xylanases XylK1 and XylK2 from Cellulosimicrobium sp. strain HY-13, both of which displayed apparent transxylosylation activity (Kim et al., 2009, 2012).

\section{CONCLUSION}

In this study, a new bimodular xylanase, XynSPP2 from Marinifilaceae bacterium strain SPP2, was expressed and characterized. It is the first xylanase characterized from the family Marinifilaceae. XynSPP2 showed maximum activity at $50^{\circ} \mathrm{C}$ and $\mathrm{pH} 6$ and was stable over a broad $\mathrm{pH}$ range and temperature lower than $50^{\circ} \mathrm{C}$. XynSPP2 displays several characteristics compared to many other characterized GH10 xylanases. First, the enzyme shares very low amino acid identity to those characterized GH10 xylanases (17-46\%). Second, it is 
a rare Fn3-fused xylanase and the Fn3 domain is beneficial to the activity of the enzyme. Third, it has a unique $-2 /-3$ subsite which updates our understanding of "polymorphisms" in the substrate binding cleft of GH10 xylanases. An Asn/Try substitution renders a strong -3 subsite in XynSPP2 which results in low activity of the enzyme toward short XOS (xylotriose). Fourth, with xylan as substrate, no detected monosaccharide is produced due to putative transxylosylation activity of XynSPP2. The substrate preference for long XOSs (>xylotriose) and the lack of monosaccharide production to a certain extent can be an advantage for XynSPP2 in prebiotic XOS production.

\section{DATA AVAILABILITY}

Publicly available datasets were analyzed in this study. This data can be found here: https://www.ncbi.nlm.nih.gov/nuccore/NZ_ AP018042.1.

\section{REFERENCES}

Aachary, A. A., and Prapulla, S. G. (2011). Xylooligosaccharides (XOS) as an emerging prebiotic: microbial synthesis, utilization, structural characterization, bioactive properties, and applications. Compr. Rev. Food Sci. Food Saf. 10, 2-16. doi: 10.1111/j.1541-4337.2010.00135.x

Almagro Armenteros, J. J., Tsirigos, K. D., Sønderby, C. K., Petersen, T. N., Winther, O., Brunak, S., et al. (2019). SignalP 5.0 improves signal peptide predictions using deep neural networks. Nat. Biotechnol 37, 420-423. doi: 10. 1038/s41587-019-0036-z

Amor, A., Parameswaran, B., Kumar, R., Birolo, L., Vinciquerra, R., Marcolongo, L., et al. (2015). Application of a new xylanase activity from Bacillus amyloliquefaciens XR44A in brewer's spent grain saccharification. J. Chem. Technol. Biotechnol. 93, 573-581. doi: 10.1002/jctb. 4589

Andrews, S. R., Charnock, S. J., Lakey, J. H., Davies, G. J., Claeyssens, M., Nerinckx, W., et al. (2000). Substrate specificity in glycoside hydrolase family 10. Tyrosine 87 and leucine 314 play a pivotal role in discriminating between glucose and xylose binding in the proximal active site of Pseudomonas cellulosa xylanase 10A. J. Biol. Chem. 275, 23027-23033. doi: 10.1074/jbc.M00012 8200

Bai, W., Xue, Y., Zhou, C., and Ma, Y. (2012). Cloning, expression and characterization of a novel salt-tolerant xylanase from Bacillus sp. SN5. Biotechnol. Lett. 34, 2093-2099. doi: 10.1007/s10529-012-1011-7

Bailey, M. J., Biely, P., and Poutanen, K. (1992). Interlaboratory testing of methods for assay of xylanase activity. J. Biotechnol. 23, 257-270. doi: 10.1016/01681656(92)90074-J

Basit, A., Liu, J., Miao, T., Zheng, F., Rahim, K., Lou, H., et al. (2018a). Characterization of two endo- $\beta-1, \quad 4$-xylanases from Myceliophthora thermophila and their saccharification efficiencies, synergistic with commercial cellulase. Front. Microbiol. 9:233. doi: 10.3389/fmicb.2018.0 0233

Basit, A., Liu, J., Rahim, K., Jiang, W., and Lou, H. (2018b). Thermophilic xylanases: from bench to bottle. Crit. Rev. Biotechnol. 38, 989-1002. doi: 10. 1080/07388551.2018.1425662

Benkert, P., Biasini, M., and Schwede, T. (2011). Toward the estimation of the absolute quality of individual protein structure models. Bioinformatics 27, 343-350. doi: 10.1093/bioinformatics/btq662

Carvalho, C. C., Phan, N. N., Chen, Y., and Reilly, P. J. (2015). Carbohydratebinding module tribes. Biopolymers 103, 203-214. doi: 10.1002/bip.2 2584

Chen, S., Kaufman, M. G., Miazgowicz, K. L., Bagdasarian, M., and Walker, E. D. (2013). Molecular characterization of a cold-active recombinant xylanase from

\section{AUTHOR CONTRIBUTIONS}

JY designed the experiments. $\mathrm{ZH}$ and FS-g conducted the experiments and analyzed the data. $\mathrm{ZH}$ wrote the manuscript.

\section{FUNDING}

This work was financially supported by the project (No. DY135-B2-06) from the China Ocean Mineral Resources R\&D Association.

\section{SUPPLEMENTARY MATERIAL}

The Supplementary Material for this article can be found online at: https://www.frontiersin.org/articles/10.3389/fmicb. 2019.01507/full\#supplementary-material

Flavobacterium johnsoniae and its applicability in xylan hydrolysis. Bioresour. Technol. 128, 145-155. doi: 10.1016/j.biortech.2012.10.087

Chen, V. B., Arendall, W. B., Headd, J. J., Keedy, D. A., Immormino, R. M., Kapral, G. J., et al. (2010). MolProbity: all-atom structure validation for macromolecular crystallography. Acta Crystallogr. D Biol. Crystallogr. 66, 12-21. doi: 10.1107/ S0907444909042073

Collins, T., Gerday, C., and Feller, G. (2005). Xylanases, xylanase families and extremophilic xylanases. FEMS Microbiol. Rev. 29, 3-23. doi: 10.1016/j.femsre. 2004.06.005

Crooks, G. E., Hon, G., Chandonia, J. M., and Brenner, S. E. (2004). WebLogo: a sequence logo generator. Genome Res. 14, 1188-1190. doi: 10.1101/gr.849004

Guillén, D., Sánchez, S., and Rodríguez-Sanoja, R. (2010). Carbohydratebinding domains: multiplicity of biological roles. Appl. Microbiol. Biotechnol. 85, 1241-1249. doi: 10.1007/s00253-0092331-y

Guo, B., Chen, X. L., Sun, C. Y., Zhou, B. C., and Zhang, Y. Z. (2009). Gene cloning, expression and characterization of a new cold-active and salttolerant endo- $\beta-1,4$-xylanase from marine Glaciecola mesophila KMM 241. Appl. Microbiol. Biotechnol. 84, 1107-1115. doi: 10.1007/s00253-0092056-y

Han, Z., Shang-Guan, F., and Yang, J. (2018). Characterization of a novel coldactive xylanase from Luteimonas species. World J. Microbiol. Biotechnol. 34, 123. doi: 10.1007/s11274-018-2505-9

Kataeva, I. A., Seidel, R. D. III, Shah, A., West, L. T., Li, X. L., and Ljungdahl, L. G. (2002). The fibronectin type 3-like repeat from the Clostridium thermocellum cellobiohydrolase CbhA promotes hydrolysis of cellulose by modifying its surface. Appl. Environ. Microbiol. 68, 4292-4300. doi: 10.1128/aem.68.9.42924300.2002

Kennedy, J., Marchesi, J. R., and Dobson, A. D. (2008). Marine metagenomics: strategies for the discovery of novel enzymes with biotechnological applications from marine environments. Microb. Cell Fact. 7:27. doi: 10.1186/1475-285 9-7-27

Khan, M. I., Sajjad, M., Sadaf, S., Zafar, R., Niazi, U. H., and Akhtar, M. W. (2013). The nature of the carbohydrate binding module determines the catalytic efficiency of xylanase Z of Clostridium thermocellum. J. Biotechnol. 168, 403408. doi: 10.1016/j.jbiotec.2013.09.010

Kim, D. R., Lim, H. K., Lee, K. I., and Hwang, I. T. (2016). Identification of a novel cellulose-binding domain within the endo3-1,4-xylanase KRICT PX-3 from Paenibacillus terrae HPL-003. Enzyme Microb. Technol. 9, 166-173. doi: 10.1016/j.enzmictec.2016. 07.014

Kim, D. Y., Ham, S. J., Kim, H. J., Kim, J., Lee, M. H., Cho, H. Y., et al. (2012). Novel modular endo-beta-1,4-xylanase with transglycosylation activity from 
Cellulosimicrobium sp. strain $H Y-13$ that is homologous to inverting GH family 6 enzymes. Bioresour. Technol. 107, 25-32. doi: 10.1016/j.biortech.2011.12.106 Kim, D. Y., Han, M. K., Oh, H. W., Bae, K. S., Jeong, T. S., Kim, S. U., et al. (2010). Novel intracellular GH10 xylanase from Cohnella laeviribosi HY-21: biocatalytic properties and alterations of substrate specificities by site-directed mutagenesis of $\operatorname{Trp}$ residues. Bioresour. Technol. 101, 8814-8821. doi: 10.1016/j.biortech.2010. 06.023

Kim, D. Y., Han, M. K., Park, D. S., Lee, J. S., Oh, H. W., Shin, D. H., et al. (2009). Novel GH10 xylanase, with a fibronectin type 3 domain, from Cellulosimicrobium sp. strain $H Y-13$, a bacterium in the gut of Eisenia fetida. Appl. Environ. Microbiol. 75, 7275-7279. doi: 10.1128/AEM.010 75-09

Kim, D. Y., Lee, S. H., Lee, M. J., Cho, H. Y., Lee, J. S., Rhee, Y. H., et al. (2018). Genetic and functional characterization of a novel GH10 endo- $\beta$ - 1,4xylanase with a ricin-type $\beta$-trefoil domain-like domain from Luteimicrobium xylanilyticum HY-24. Int. J. Biol. Macromol. 106, 620-628. doi: 10.1016/j. ijbiomac.2017.08.063

Kim, H., Jung, K. H., and Pack, M. Y. (2000). Molecular characterization of xynX, a gene encoding a multidomain xylanase with a thermostabilizing domain from Clostridium thermocellum. Appl. Microbiol. Biotechnol. 54, 521-527. doi: 10.1007/s00253000 0412

Kumar, S., Stecher, G., and Tamura, K. (2016). MEGA7: molecular evolutionary genetics analysis version 7.0 for bigger datasets. Mol. Biol. Evol. 33, 1870-1874. doi: 10.1093/molbev/msw054

Lee, S. H., and Lee, Y. E. (2014). Cloning and characterization of a multidomain GH10 xylanase from Paenibacillus sp. DG-22. J. Microbiol. Biotechnol. 24, 1525-1535. doi: 10.4014/jmb.1407.07077

Li, N., Shi, P., Yang, P., Wang, Y., Luo, H., Bai, Y., et al. (2009). A xylanase with high $\mathrm{pH}$ stability from Streptomyces sp. S27 and its carbohydrate-binding module with/without linker-region-truncated versions. Appl. Microbiol. Biotechnol. 83, 99-107. doi: 10.1007/s00253-008-1810-x

Linares-Pasten, J. A., Aronsson, A., and Karlsson, E. N. (2018). Structural considerations on the use of endo-xylanases for the production of prebiotic xylooligosaccharides from biomass. Curr. Protein Pept. Sci. 19, 48-67. doi: 10.2174/138920371766616092315 5209

Lombard, V., Golaconda Ramulu, H., Drula, E., Coutinho, P. M., and Henrissat, B. (2014). The carbohydrateactive enzymes database (CAZy) in 2013. Nucl. Acids Res. 42, 490-495. doi: 10.1093/nar/gkt1178

Marchler-Bauer, A., Bo, Y., Han, L., He, J., Lanczycki, C. J., Lu, S., et al. (2017). CDD/SPARCLE: functional classification of proteins via subfamily domain architectures. Nucleic Acids Res. 45, D200-D203. doi: 10.1093/nar/gkw1129

Marx, J. C., Collins, T., D’Amico, S., Feller, G., and Gerday, C. (2007). Cold-adapted enzymes from marine Antarctic microorganisms. Mar. Biotechnol. 9, 293-304. doi: 10.1007/s10126-006-6103-8

Morgan, N. K., Wallace, A., Bedford, M. R., and Choct, M. G. (2017). Efficiency of xylanases from families 10 and 11 in production of xylooligosaccharides from wheat arabinoxylans. Carbohydr. Polym. 167, 290-296. doi: 10.1016/j.carbpol. 2017.03.063

Ndou, S. P., Kiarie, E., Agyekum, A. K., Heo, J. M., Romero, L. F., Arent, S., et al. (2015). Comparative efficacy of xylanases on growth performance and digestibility in growing pigs fed wheat and wheat bran or corn and corn DDGSbased diets supplemented with phytase. Anim. Feed Sci. Tech. 209, 230-239. doi: 10.1016/j.anifeedsci.2015.08.011

Nguyen, S. T. C., Freund, H. L., Kasanjian, J., and Berlemont, R. (2018). Function, distribution, and annotation of characterized cellulases, xylanases, and chitinases from CAZy. Appl. Microbiol. Biotechnol. 102, 1629-1637. doi: 10.1007/s00253-018$8778-y$

Nieto-Domínguez, M., de Eugenio, L. I., York-Durán, M. J., Rodríguez-Colinas, B., Plou, F. J., Chenoll, E., et al. (2017). Prebiotic effect of xylooligosaccharides produced from birchwood xylan by a novel fungal GH11 xylanase. Food Chem. 232, 105-113. doi: 10.1016/j.foodchem.2017.03.149

Nordberg Karlsson, E., Schmitz, E., Linares-Pastén, J. A., and Adlercreutz, P. (2018). Endo-xylanases as tools for production of substituted xylooligosaccharides with prebiotic properties. Appl. Microbiol. Biotechnol. 102, 9081-9088. doi: 10.1007/s00253-018-9343-4

Pell, G., Szabo, L., Charnock, S. J., Xie, H., Gloster, T. M., Davies, G. J., et al. (2004). Structural and biochemical analysis of Cellvibrio japonicus xylanase 10C: how variation in substrate-binding cleft influences the catalytic profile of family GH-10 xylanases. J. Biol. Chem. 279, 11777-11788. doi: 10.1074/jbc. M311947200

Pollet, A., Delcour, J. A., and Courtin, C. M. (2010). Structural determinants of the substrate specificities of xylanases from different glycoside hydrolase families. Crit. Rev. Biotechnol. 30, 176-191. doi: 10.3109/0738855100364 5599

Sakka, M., Higashi, Y., Kimura, T., Ratanakhanokchai, K., and Sakka, K. (2011). Characterization of Paenibacillus curdlanolyticus B-6 Xyn10D, a xylanase that contains a family 3 carbohydrate-binding module. Appl. Environ. Microbiol. 77, 4260-4263. doi: 10.1128/AEM.002 26-11

Santiago, M., Ramírez-Sarmiento, C. A., Zamora, R. A., and Parra, L. P. (2016). Discovery, molecular Mechanisms, and industrial applications of cold-active enzymes. Front. Microbiol. 7:1408. doi: 10.3389/fmicb.2016.01408

Schmidt, A., Gübitz, G. M., and Kratky, C. (1999). Xylan binding subsite mapping in the xylanase from Penicillium simplicissimum using xylooligosaccharides as cryoprotectant. Biochemistry 38, 2403-2412. doi: 10.1021/bi982 1081

Sermsathanaswadi, J., Baramee, S., Tachaapaikoon, C., Pason, P., Ratanakhanokchai, K., and Kosugi, A. (2017). The family 22 carbohydrate-binding module of bifunctional xylanase/ $\beta$-glucanase Xyn10E from Paenibacillus curdlanolyticus B-6 has an important role in lignocellulose degradation. Enzyme Microb. Technol. 96, 75-84. doi: 10.1016/j.enzmictec.2016.09.015

Sievers, F., Wilm, A., Dineen, D. G., Gibson, T. J., Karplus, K., Li, W., et al. (2011). Fast, scalable generation of high-quality protein multiple sequence alignments using Clustal Omega. Mol. Syst. Biol 7, 539. doi: 10.1038/msb.20 11.75

Studier, F. W. (2005). Protein production by auto-induction in high-density shaking cultures. Prot. Exp. Pur. 41, 207-234. doi: 10.1016/j.pep.2005.01.016

Talamantes, D., Biabini, N., Dang, H., Abdoun, K., and Berlemont, R. (2016). Natural diversity of cellulases, xylanases, and chitinases in bacteria. Biotechnol. Biofuels. 9, 133. doi: 10.1186/s13068-016-0538-6

Thomas, L., Sindhu, R., Binod, P., and Pandey, A. (2015). Production of an alkaline xylanase from recombinant Kluyveromyces lactis (KY1) by submerged fermentation and its application in bio-bleaching. Biochem. Eng. J. 102, 24-30. doi: 10.1016/j.bej.2015.02.008

Trincone, A. (2011). Marine biocatalysts: enzymatic features and applications. Mar. Drugs 9, 478-499. doi: 10.3390/md9040478

Tuck, C. O., Perez, E., Horvath, I. T., Sheldon, R. A., and Poliakoff, M. (2012). Valorization of biomass: deriving more value from waste. Science 337, 695-699. doi: $10.1126 /$ science. 1218930

Van Dyk, J., and Pletschke, B. (2012). A review of lignocellulose bioconversion using enzymatic hydrolysis and synergistic cooperation between enzymesfactors affecting enzymes, conversion and synergy. Biotechnol. Adv. 30, 14581480. doi: 10.1016/j.biotechadv.2012.03.002

Verma, D., and Satyanarayana, T. (2012). Cloning, expression and applicability of thermoalkali-stable xylanase of Geobacillus thermoleovorans in generating xylooligosaccharides from agro-residues. Bioresour. Technol. 107, 333-338. doi: 10.1016/j.biortech.2011.12.055

Wang, S. Y., Hu, W., Lin, X. Y., Wu, Z. H., and Li, Y. Z. (2012). A novel cold-active xylanase from the cellulolytic myxobacterium Sorangium cellulosum So97331: gene cloning, expression, and enzymatic characterization. Appl. Microbiol. Biotechnol. 93, 1503-1512. doi: 10.1007/s00253-011-3480-3

Watanabe, M., Kojima, H., and Fukui, M. (2018). Complete genome sequence of Marinifilaceae bacterium strain SPP2, isolated from the Antarctic marine sediment. Mar. Genomics 39, 1-2. doi: 10.1016/j.margen.2017. 06.006

Watanabe, T., Ito, Y., Yamada, T., Hashimoto, M., Sekine, S., and Tanaka, H. (1994). The roles of the $\mathrm{C}$-terminal domain and type III domains of chitinase A1 from Bacillus circulans WL-12 in chitin degradation. J. Bacteriol. 176, 4465-4472. doi: $10.1128 /$ jb.176.15.4465-4472.1994 
Waterhouse, A., Bertoni, M., Bienert, S., Studer, G., Tauriello, G., Gumienny, R., et al. (2018). SWISS-MODEL: homology modelling of protein structures and complexes. Nucleic Acids Res. 46, W296-W303. doi: 10.1093/nar/gky427

Zhao, Y., Meng, K., Luo, H., Huang, H., Yuan, T., Yang, P., et al. (2013). Molecular and biochemical characterization of a new alkaline active multidomain xylanase from alkaline wastewater sludge. World J. Microbiol. Biotechnol. 29, 327-334. doi: 10.1007/s11274-012-1186-Z

Zhou, J., Dong, Y., Tang, X., Li, J., Xu, B., Wu, Q., et al. (2012). Molecular and biochemical characterization of a novel intracellular low-temperature-active xylanase. J. Microbiol. Biotechnol. 22, 501-509. doi: 10.4014/jmb.1108.08006
Conflict of Interest Statement: The authors declare that the research was conducted in the absence of any commercial or financial relationships that could be construed as a potential conflict of interest.

Copyright (c) 2019 Han, Shang-guan and Yang. This is an open-access article distributed under the terms of the Creative Commons Attribution License (CC BY). The use, distribution or reproduction in other forums is permitted, provided the original author(s) and the copyright owner(s) are credited and that the original publication in this journal is cited, in accordance with accepted academic practice. No use, distribution or reproduction is permitted which does not comply with these terms. 